\title{
Correction to: Biochemical response and nutrient uptake of two arbuscular mycorrhiza-inoculated chamomile varieties under different osmotic stresses
}

Fatemeh Ebrahimi ${ }^{1}$, Amin Salehi ${ }^{1 *}$, Mohsen Movahedi Dehnavi ${ }^{1}$, Amin Mirshekari $^{1}$, Mohammad Hamidian $^{1}$ and Saeid Hazrati ${ }^{2}$

\section{Correction to: Botanical Studies (2021) 62:22}

https://doi.org/10.1186/s40529-021-00328-3

Following publication of the original article (Ebrahimi et al. 2021), errors were identified in Tables 1 and 4, The data are reversed in Tables 1 and 4 and the right decimal place is moved to the left decimal place.

The correct tables are given below.

1 Department of Agronomy and Plant Breeding, Faculty of Agriculture,

Yasouj University, Yasouj, Iran

Full list of author information is available at the end of the article 


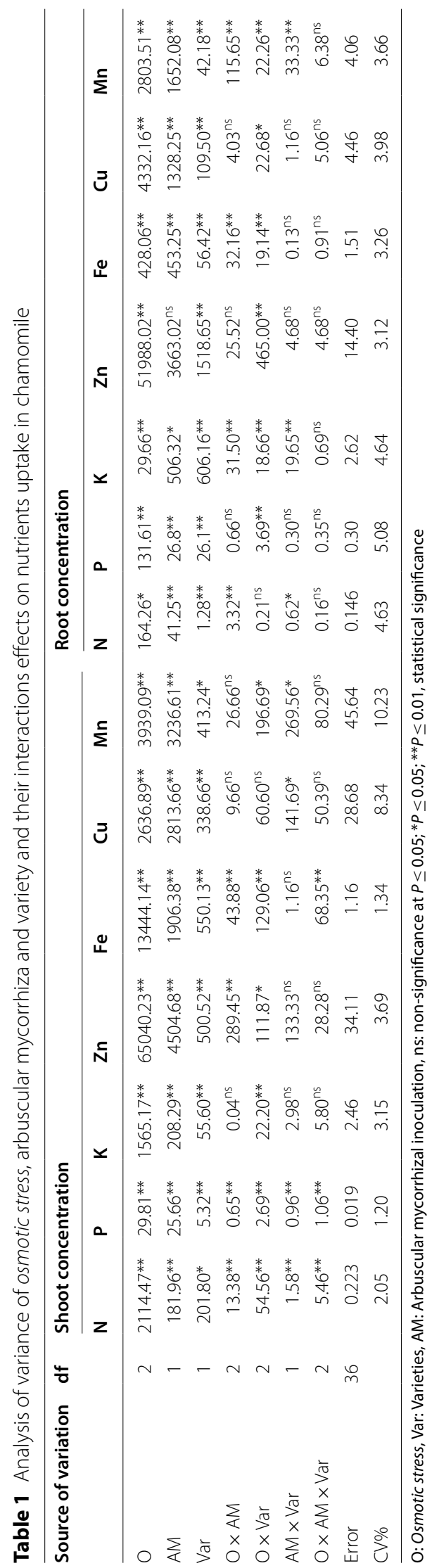


Table 4 Analysis of variance of osmotic stress, arbuscular mycorrhiza and variety and their interactions effects on osmolytes, activity of antioxidant enzymes (catalase (CAT), peroxidase (POD), polyphenol oxidase (PPO)), and shoot and root dry weights

\begin{tabular}{lcccccccc}
\hline Source of variation & df & Proline & Total soluble sugar & CAT & POD & PPO & Shoot dry weight & Root dry weight \\
\hline O & 2 & $136.50^{* *}$ & $36248.39^{* *}$ & $3864.92^{* *}$ & $2.62^{* *}$ & $217.80^{* *}$ & $1.09^{* *}$ & $0.002^{* *}$ \\
AM & 1 & $16.54^{* *}$ & $2693.25^{* *}$ & $281.51^{* *}$ & $0.13^{* *}$ & $36.63^{* *}$ & $0.083^{* *}$ & $0.008^{* *}$ \\
$\operatorname{Var}$ & 1 & $30.56^{* *}$ & $753.58^{* *}$ & $210.45^{* *}$ & $0.34^{* *}$ & $33.87^{* *}$ & $0.015^{* *}$ & $0.00086^{* *}$ \\
O $\times$ AM & 2 & $1.12^{* *}$ & $419.88^{* *}$ & $26.07^{* *}$ & $0.009^{* *}$ & $4.40^{* *}$ & $0.017^{* *}$ & $0.00083^{* *}$ \\
O $\times \operatorname{Var}$ & 2 & $0.04^{* *}$ & $79.14^{* *}$ & $43.14^{* *}$ & $0.09^{* *}$ & $6.19^{* *}$ & $0.148^{* *}$ & $0.0001^{* *}$ \\
AM $\times \operatorname{Var}$ & 1 & $0.44^{* *}$ & $6.87^{\text {ns }}$ & $2.59^{\text {ns }}$ & $0.01^{* *}$ & $1.35^{* *}$ & $0.0068^{* *}$ & $0.0003^{* *}$ \\
O $\times$ AM $\times \operatorname{Var}$ & 2 & $0.43^{* *}$ & $17.17^{\text {ns }}$ & $8.18^{* *}$ & $0.013^{* *}$ & $0.9^{* *}$ & $0.0058^{* *}$ & $0.00009^{\text {ns }}$ \\
Error & 36 & 0.006 & 7.40 & 0.832 & 0.0003 & 0.126 & 0.0001 & 0.00003 \\
CV\% & & 1.32 & 2.92 & 4.41 & 3.46 & 5.08 & 2.25 & 5.88
\end{tabular}

O: Osmotic stress, Var:Varieties, AM: Arbuscular mycorrhizal inoculation, ns: non-significance at $P \leq 0.05 ;{ }^{*} P \leq 0.05 ; * * P \leq 0.01$, statistical significance

\section{Author details}

${ }^{1}$ Department of Agronomy and Plant Breeding, Faculty of Agriculture, Yasouj University, Yasouj, Iran. ${ }^{2}$ Department of Agronomy, Faculty of Agriculture,

Azarbaijan Shahid Madani University, Tabriz, Iran.

Published online: 05 March 2022

\section{Reference}

Ebrahimi F, Salehi A, Movahedi Dehnavi M, Mirshekari A, Hamidian M, Hazrati S (2021) Biochemical response and nutrient uptake of two arbuscular mycorrhiza-inoculated chamomile varieties under different osmotic stresses. Bot Stud 62:22. https://doi.org/10.1186/s40529-021-00328-3

\section{Publisher's Note}

Springer Nature remains neutral with regard to jurisdictional claims in published maps and institutional affiliations. 